\title{
Culture and Health: The Effect of Nupe Cultural Practice on the Health of Nupe People
}

\author{
${ }^{*}$ E.O. O. Oleribe B.Sc, MBBS, MPH, MBA, ${ }^{* *} D$ D Alasia MBBCh, MWACP \\ Department of *Community Medicine, University of Nigeria Teaching Hospital Enugu, Enugu State, Nigeria, \\ ${ }^{* *}$ Internal Medicine, University of Port Harcourt Teaching Hospital, Port Harcourt Nigeria.
}

\begin{abstract}
Background: The Cultural practices of communities are known to influence the Health status of the community both positively and negatively. To achieve set out health goals positive cultural practices should be enhanced and incorporated into community based health programmes. This commentary aims to highlight the positive and negative effects of cultural practices on health using the Nupes a tribe in North central Nigeria as a reference point.
\end{abstract}

Method: Information on the cultural practice of Nupe people and the related health effects were obtained through observation, group discussion and interviews among Katcha people, a Nupe community in Niger state of Nigeria. Literature of the effects of cultural practices on health was reviewed using MEDLINE and manual library search.

Results: Cultural practices with positive health effects such a "Tamako" a system of community based assistance to the sick was found among the Nupes in Katcha. This system is useful in defraying hospital bills of indigent members of the community. Another positive practice is the culture of food assistance and gifts to nursing mothers which helps to improve their nutritional status. However Negative cultural practices such as child marriage, "Sadakiar" (wife gifts), "Egikpa" (child fostering) and "Efidan" (body scarifications) are also practiced.Conclusion: Cultural practices have significant effects on health. Most of these effects are detrimental and should be discouraged. Cultural practices with positive effects should be encouraged and integrated into community based health policies and programmes in order to enhance the attainment of the millennium development goals especially in rural communities of the developing world.

KEYWORDS: Culture and health; Nupe; Nigeria.

Paper accepted for publication 16th May 2006.

\section{INTRODUCTION}

Over the years, the effects of culture on health have been well documented ${ }^{1,3}$. Cultural practices affecting the health of communities have been classified into positive, negative and neutral cultural practices with respect to their effects on the health of individuals ${ }^{1}$.
While positive cultures such as breast feeding are said to enhance health, negative ones like female genital cutting have adverse effect on health ${ }^{4}$ and neutral ones such as the use of beads around the waist of females have no significant effect on health ${ }^{1}$.

The Nupe community is a very cultural community with several cultural practices that are harmful, beneficial or neutral to health. This study aims to highlight the positive and negative effects of cultural practices on health using the Nupes a tribe in North central Nigeria as a reference point.

\section{Study setting and Method}

This is a qualitative study, employing simple observations, group discussions and in-depth key informant interviews. The study was carried out in Katcha Local Government Area of Niger State. Majority of study population were indigenes who sought for care at the Katcha community health centre and their relatives. Community opinion leaders were also consulted and interviewed. The information obtained from observation and interviews was made open to educated indigenes for correction of misinformation, improvement of facts and additions where necessary.Most of the indigenes were farmers, traders or pastoralist with low level of formal education. Very few indigenes had formal education and these groups of people were usually civil servants, school teachers and community based health workers.

\section{Observation and Discussion}

The Nupe community in Katcha local government has a lot of cultural practices with significant positive and negative health effects.

\section{Positive cultural practices}

Tamako: Tamako in Nupe dialect simply means 'gift assistance'. It can be used in several situations in request for help, however in relation to the sick and hospital care it represents all forms of assistance which could be monetary and otherwise rendered to the sick while on treatment in a hospital by friends and relations in order to reduce the cost of healthcare services. This practice makes hospital care more tolerable, reduces the overall stress on the immediate family of the sick 
person, minimizes effects of family dislocation, augment finances and re-establishes stable family psychodynamics.

This culture requires friends and associates not only to visit the sick while on admission, but to contribute willingly to his or her treatment either in cash or in kind. Although the amount presented is not established by law, everyone is expected to give according to the person's economic standing in the community which is known to all members of the community. Those who cannot offer monetary assistance, present gifts like water, fire-wood and meals and may opt to stay with the patient in the hospital to meet his/her daily needs.

This cultural practice also demands members of the community to visit the sick one as often as possible. In some communities, such visits are mandatory and anyone who fails to visit or contribute willingly is looked on as either a bad person or the cause of the illness.

Monies and gifts realized from this culture are reinvested in the care of the sick. They maybe used to defray hospital bills or utilized in providing the daily needs of the sick. The fire-wood and water are used to bathe the sick while those staying in the hospital run errands for the sick and her/his family.

Another form of Tamako is the 'foods assist' culture seen within a few days to weeks of delivery where other women in the community present food gifts to the new mother to help her recover from the losses of pregnancy and child birth. This system helps to provide adequate nutrition for the nursing and lactating mother.

Tamako is one cultural practice with positive health effects that should be encouraged and if possible harvested and modified to accelerate community acceptance of the National Health Insurance Scheme (NHIS) ${ }^{5}$ community social insurance scheme.

\section{Negative cultural practices}

Bi-medication: Bi-medication refers to the use of more than one group of drugs from two or more different healthcare providers ${ }^{6}$. It is one culture that is as common as medical practice and as old as orthodox medical care in Africa. It is not uncommon to see sick people and their families combining drugs from orthodox medical care with those from traditional healers, or combining any of the above with those from religious/faith based centers.

This practice is a product of African cultural beliefs whose explanation of the aetiology of illness, in addition to taking cognizance of the physical world, also incorporates psychic and metaphysical factors ${ }^{6.8}$. There have been previous reports of cases where hospitalized patients secretly have their relations bring alternative/traditional medicine to them, ${ }^{9}$. In the practice of bi-medication patients are encouraged by their relatives to combine hospital medication in association with traditional medication. It is thus not uncommon to hear a relation telling his/her sick relative that their present illness cannot be solved by orthodox medicine." This practice is very common in this community.

The dangers of bi-medication are reduced drug effectiveness which may lead to untoward effects. Such unprocessed drug combinations may exaggerate the expected effects of the prescribed drugs, produce unexpected side effects, cancel the pharmacological benefits or mask the expected results. The drugs which are usually unprocessed and unrefined herbal concoctions which could be alcohol or water based may contain toxins with adverse effects to the liver and the kidneys as herbal induced kidney disease contributes significantly to the burden of acute and chronic renal failure in Nigeria. ${ }^{11}$. This practice of bi-medication as we observed may have contributed to the death of a 35 year female hypertensive on anti-hypertensive therapy with good blood pressure control who after ingestion of a herbal concoction from traditional healer developed constipation, abdominal distension, anuria and finally death. This culture should be discouraged.

Child marriage: Child marriage represents a very common form of child abuse ${ }^{12}$ which is still widely practiced with some cultures and religions encouraging the practice. It is defined as the betrothal or marriage of a person less than 18 years of age with or without her consent. This practice is carried out sometimes for economic or other gains ${ }^{12}$.

The culture of child marriage still persists in Katcha. The adverse health and social implications of this cultural practice are enormous. The education of these children is truncated denying them the opportunity to optimize their potential in life, thus they become mothers when they themselves are still children seeking parental guide. Most of them are married into polygamous settings with increasing risk of transmission of sexually transmitted infection and HIV. To become mothers, they go through life threatening complications like obstructed labour, intrauterine foetal deaths, uterine rupture, vesico-vaginal fistula, rectovaginal fistula because of their poorly developed pelvic bones and resultant cephalo-pelvic disproportion with the risk of maternal and neonatal deaths. It is not therefore surprising that a lot of Katcha women have had at least one miscarriage and or one infant death ${ }^{12}$. 
Another cultural dimension of child marriage is sadakiar. This simply put means 'wife gift' which could be total or partial sadakiar. When the gift of a girl to man (most times a boy) goes with full a marriage ceremony, it is referred to as total sadakiar but if only the bride price is waved, it becomes partial sadakiar. This cultural practice extends child marriage in Nupe land to boys, where an underage school boy is given a girl for wife by his father, mother or the girl's parents as a gift. It is therefore not surprising to see primary school boys having two wives gotten as gifts from their parents.

The challenge of family life robs them of their chance at education and makes them dependent on parental sustenance and assistance.

Egikpa: Egikpa is a Nupe word meaning 'caretaker'. All over the world, child fostering exists in one form or the other. In Africa, for instance, it is a common practice; encouraged by the extended family system ${ }^{12}$. It is defined as the relocation or transfer of a child from his/her biological parents or family of orientation to another place where he/she is made to reside, grow and is cared for by foster parents for economic or socialization purposes without adequate concurrent transfer of parental rights and obligations ${ }^{12}$.

The Nupe culture allows a family to give out one of their children especially the first child to a relation to cater for and to train. The culture disallows the child's parents from taking care of their first child as long as the child's grand parents are alive. Since polygamy is common in Nupe land it is an exception to find a monogamous family setting. Thus these relations already have large families that they can hardly take care of; therefore an additional mouth will be an extra burden to the family. In spite of the burden placed on the families by this system the culture prohibits refusal of such request for fostering. Thus the families accept these children but are unable to provide them with good education and health care services, proper nutrition and parental care. Consequently the poor socioeconomic status of the families hamper proper care seeking behavoiur when the children are ill thus ill children present to hospital in the terminal stage of illness after prolonged periods of home and alternative medical treatment.

Efidan: Efidan in Nupe means scarifications. The practice of scarification on the face, neck and arms and other parts of the body is a strong part of Nupe culture. These marks which are imposed for the purposes of identification are also believed to prevent illness such as meningitis and mental problems.

These marks are also used in the treatment of children with febrile convulsions who have extensive scarifications which are covered with sand based herbal preparations and hot concoctions which in some cases result in extensive burns on the children leading to death in a few cases from burns and infection.

The health consequences of this practice are the risk of transmission of HIVIAIDS infection, hepatitis virus and other deadly blood borne diseases. In some cases the blood loss is significant leading to anemia. The possibility of tetanus, other superimposing infection (which may lead to death) and keliod formation are added complications.

Like abdominal massage in pregnant women ${ }^{13}$, ignorance, illiteracy and poverty have sustained this practice. Legislation may be necessary to curb this practice as was done with female genital mutilation ${ }^{14,15}$.

Others: Other cultural practices seen in Katcha include $\square \quad$ Rejection of parenteral drugs. Superstitious belief amongst katcha people leads to the rejection of medications administered parentally especially in children as it is believed to be responsible for childhood fungal infection seen in the flexural surfaces especially in the groin and perineum called "enyezduru" in the local language. As a result of this women bring their severely ill children to the clinic with instructions from their spouses prohibiting their wards or children form receiving injections. The culture claims that injections worsens the problem and sometimes kills the child. This deprives severely ill children of appropriate life saving treatment. Unless this culture is stopped, more children will die from parental refusal in accepting life saving treatment options.

\section{CONCLUSION}

A lot of cultural practices among communities in the developing world have negative effects on health; however there are cultural practices with positive health effects. While good cultural practices should be promoted effective action is required to reduce the impact of these negative cultural practices on people's health. Massive community education with community involvement is required to effect such change. Cultural practices with positive effects should be encouraged and integrated into community based health policies and programmes in order to enhance the attainment of the millennium development goals especially in rural communities of the developing world.

\section{REFERENCES}

1. Erinosho OA. Health Sociology for Universities, Colleges and Health related Institutions. Ibadan, Nigeria ;Sam Bookman,1998:17-20. 
2. Yap PM. Mental disease peculiar to certain cultures: A survey of comparative Psychiatry. J Mental Sci 1951:97:331-27.

3. Lambo TA. The Role of Cultural Factors in Paranoid Psychosis among the Yoruba Tribe. J Mental Sci. 1955;101:239-66.

4. Abubakar IS, lliyasu Z, Kabir M, Uzoho CC, Abdulkadir MB. Knowledge, attitude and practice of Female genital cutting among antenatal patients in Aminu Kano Teaching Hospital Kano. Nig J Med 2004; 13(3):254 258.

5. National Health Insurance Scheme (NHIS). Operational guidelines. A publication of the National Health Insurance Commission, Abuja, Nigeria 2005:77-84.

6. Oke EA. Traditional health services: an investigation of the provider and the level and pattern of utilization among the Yoruba. Dept of Sociology, University of Ibadan. Ibadan Sociological Series 1995:1.

7. Erinosho OA. The relevance of social sciences to health care delivery in tropical Africa. In Ola Rof, Osemwota $\mathrm{O}$. Management of problems of primary healthcare in Nigeria. Benin, University of Benin. 2002.161-174.

8. Agbonlahor FI. Integration of the traditional healer into the main stream of our health care delivery services: an appraisal. In Ola Rof, Osemwota O. Management of problems of primary Healthcare in Nigeria. Benin, University of Benin. 175-180

9. Asunni T. The dilemma of traditional healing with special reference to Nigeria. Social Sciences and Medicine. 1979:13B.

10. Osuntokun BO. The traditional basis of Neuropsychiatric practice among the Yoruba of Nigeria. Trop Georg Med 1975;27:

11. Adelekun $O E$. A retrospective study of the aetiology of Acute 'Renal failure. WAJM 1999; 18:60 -62.

12. Oleribe OEO. The concept of child abuse. An Anti-Child Abuse Society of Africa (ACASA) publication. Abuja. National War College Press. 2002:10-137.

13. Ugboma HAA, Akani Cl. Abdominal massage: another cause of maternal mortality. Nig J Med 2004; 13(3):259 262.

14. WHO. Female circumcision. World Health Organization (WHO) Chronicles. 1986; 40(1):31-36.

15. Hosken FP. The Report: Genital and sexual mutilation of females. Women's Intenational network news, 1993:6(3):4-6. 